\title{
Purification of the recombinant green fluorescent protein from tobacco plants using alcohol/salt aqueous two-phase system and hydrophobic interaction chromatography
}

\author{
Jie Dong ${ }^{1,2,3}$, Xiangzhen Ding ${ }^{1,2,3}$ and Sheng Wang ${ }^{1,2,3^{*}}$ (1)
}

\begin{abstract}
Background: The green fluorescent protein (GFP) has been regarded as a valuable tool and widely applied as a biomarker in medical applications and diagnostics. A cost-efficient upstream expression system and an inexpensive downstream purification process will meet the demands of the GFP protein with high-purity.

Results: The recombinant GFP was transiently expressed in an active form in agoinoculated Nicotiana benthamiana leaves by using Tobacco mosaic virus (TMV) RNA-based overexpression vector (TRBO). The yield of recombinant GFP was up to $\sim 60 \%$ of total soluble proteins (TSP). Purification of recombinant GFP from the clarified lysate of $N$. benthaniana leaves was achieved by using an alcohol/salt aqueous two-phase system (ATPS) and following with a further hydrophobic interaction chromatography $(\mathrm{HIC})$. The purification process takes only $\sim 4 \mathrm{~h}$ and can recover $34.1 \%$ of the protein. The purity of purified GFP was more than $95 \%$ and there were no changes in its spectroscopic characteristics.

Conclusions: The strategy described here combines the advantages of both the economy and efficiency of plant virus-based expression platform and the simplicity and rapidity of environmentally friendly alcohol/salt ATPS. It has a considerable potential for the development of a cost-efficient alternative for production of recombinant GFP.
\end{abstract}

Keywords: Green fluorescent protein, Plant virus, Transient gene expression, Aqueous two-phase system, Hydrophobic interaction chromatography

\section{Background}

Green fluorescent protein (GFP) was originally derived from jellyfish Aequorea victoria species, which exhibit an intensely natural fluorescence [1]. GFP has been regarded as a valuable tool in the field of biology and biotechnology [2]. Due to its widespread application as a molecular biomarker [3, 4], there is an increase in the demand for GFP with high-purity.

\footnotetext{
* Correspondence: wang_s@nxu.edu.cn

'Key Laboratory of Ministry of Education for Protection and Utilization of Special Biological Resources in the Western China, Yinchuan 750021, People's Republic of China

${ }^{2}$ Key Laboratory of Modern Molecular Breeding for Dominant and Special

Crops in Ningxia, Yinchuan 750021, People's Republic of China

Full list of author information is available at the end of the article
}

Through the application of DNA recombinant technology, GFP has successfully been produced by a variety of hosts [5]. Currently, the commercially available GFP produced by Escherichia coli costs approximately US\$2000.00 per mg [6]. A cost-efficient upstream expression system and an inexpensive downstream purification process will be able to reduce the production costs and thereby meet the demands of the GFP with high-purity. Plants have been regarded as excellent biofactories for producing recombinant proteins of interest for research, pharma and industry [7]. It was estimated that proteins can be produced in plants at a cost of 10-50 fold less than in Escherichia coli [8]. Virus-based expression system can express the target proteins in plants at an extremely high level because of viral

(c) The Author(s). 2019 Open Access This article is distributed under the terms of the Creative Commons Attribution 4.0 International License (http://creativecommons.org/licenses/by/4.0/), which permits unrestricted use, distribution, and reproduction in any medium, provided you give appropriate credit to the original author(s) and the source, provide a link to the Creative Commons license, and indicate if changes were made. The Creative Commons Public Domain Dedication waiver (http://creativecommons.org/publicdomain/zero/1.0/) applies to the data made available in this article, unless otherwise stated. 
amplification [9]. In addition, plant platform offers an ecofriendly way to produce recombinant proteins largely due to low energy requirements and $\mathrm{CO}_{2}$ emission [10].

In order to achieve a high level of purity, diverse chromatographic techniques have been used to purify the recombinant GFP. In general, these chromatographic methods involve multistep, timeconsuming and complicated operations, resulting in a higher purification cost [5]. Thus, an inexpensive method for GFP purification is highly needed. Aqueous two-phase system (ATPS) has been widely regarded as an alternative way for the separation and purification of proteins and other biomolecules [11]. Significant efforts have been made to develop different type of ATPSs and their applications in purification of various biomaterials [12]. Alcohol/salt ATPS is one of the promising members of the ATPS family [13]. The advantages of alcohol/salt ATPS include low cost, fast phase separation, simple operational procedures and easy scale-up [14]. Furthermore, this type of ATPS has an environmental friendliness aspect as ethanol and salt can be recycled via conventional processes [15].

Considering the excellent capabilities of plant viral expression vector and alcohol/salt ATPS, this work aimed to develop a cost-effective alternative for production of recombinant GFP. Plant viral ampliconbased gene expression system [16] was employed to transiently express recombinant GFP in Nicotiana benthamiana leaves by agroinfiltration. Subsequently, purification of GFP was achieved by combining an alcohol/salt ATPS stage with a further hydrophobic interaction chromatography (HIC) step. The GFP extraction efficiencies of each step were determined, and their purification aptitudes were evaluated. The fluorescence characterization of purified GFP was measured by using both gel-based imaging and the spectrofluorometric method.

\section{Results}

Transient expression of recombinant GFP in $N$. benthamiana leaves

The pJL TRBO-G vector (Fig. 1) was agoinoculated into $N$. benthamiana leaves in the presence of the suppressor of silencing P19. At 4-8 days after inoculation, high intensity of green fluorescence in the inoculated leaves was observed after illumination with long wave UV light (Fig. 2a). The cells exhibiting strong GFP signal could be seen in almost all cells in the agroinfected leaf area when examined under a fluorescence microscope (Fig. 2b). A protein corresponding to the expected molecular weight $(27 \mathrm{kDa})$ was detected in the total soluble proteins extracted from the inoculated leaf tissues by both Coomassie stained polyacrylamide gel (Fig. 2c) and Western blot analysis (Fig. 2d). No signals were detected in samples from non-inoculated leaves (Fig. 2d). The GFP yield was up to $\sim 60 \%$ of total soluble proteins (Table 1 ). All results together indicated that the recombinant GFP was successfully and efficiently expressed in the $N$. benthamiana leaves. The overexpression of GFP by plant amplicon-based vector provided a good foundation for the downstream purification of recombinant GFP.

\section{Purification of GFP from N. benthamiana leaves}

A procedure using alcohol/salt ATPS and HIC was applied for the isolation and purification of GFP from the inoculated $N$. benthamiana leaves.

The alcohol/salt ATPS was performed by a two-step procedure. In the first step, the GFP was exclusively extracted into ethanol phase. The GFP fluorescence in the upper ethanol phase was clearly observed upon UV illumination after phase separation (Fig. 3a2). A thin layer of host cellular proteins was observed at the interphase (Fig. 3a2). In addition, analysis by Coomassie-stained polyacrylamide gel electrophoresis

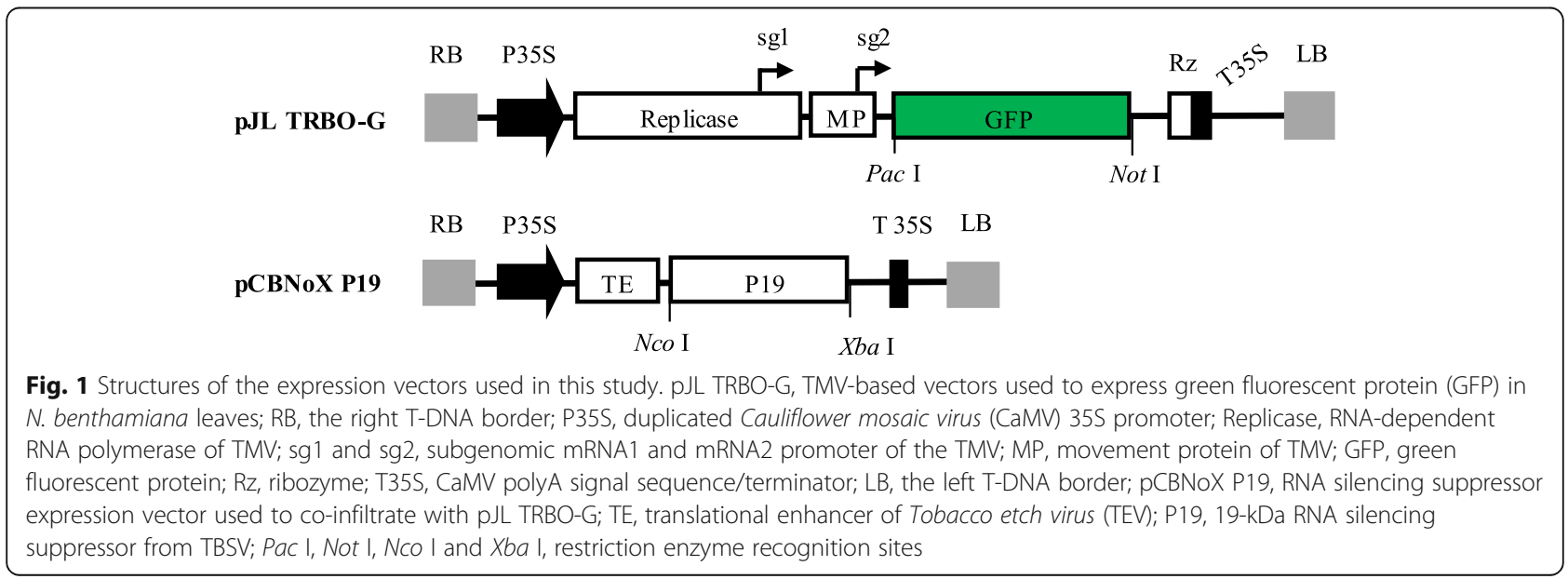



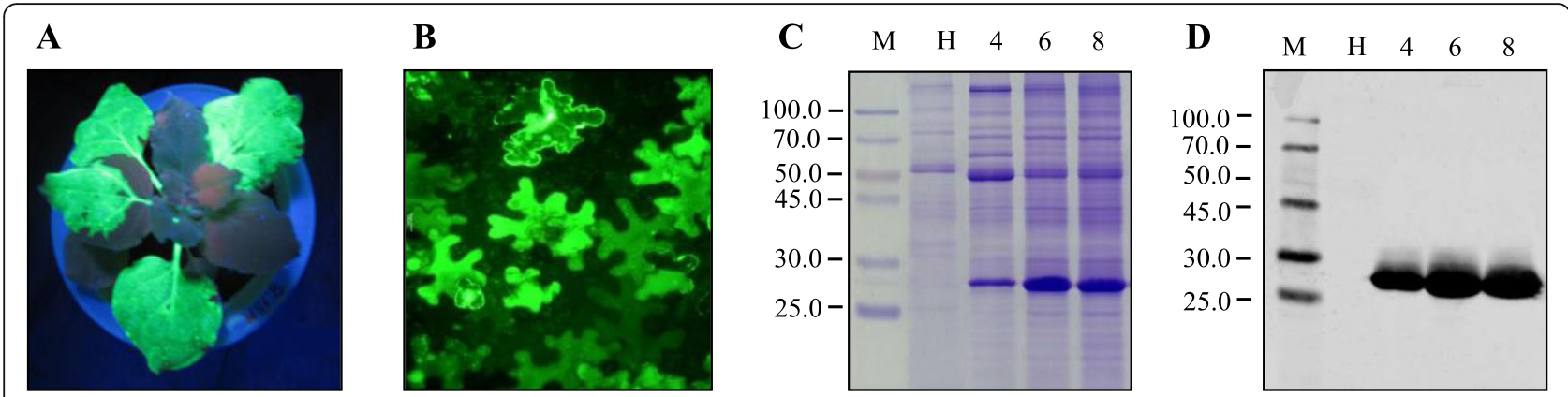

Fig. 2 Analysis of accumulation of recombinant GFP in N. benthamiana. a Representative TMV vector-infiltrated N. benthamiana leaves under UVillumination at 8 days post-inoculation (dpi). $\mathbf{b}$ Confocal microscopy image of GFP in infiltrated leaves. Green signal in image is due to GFP fluorescence. c Coomassie-stained polyacrylamide gel showing GFP accumulation in infiltrated $N$. benthamiana leaves. M, protein molecular weight marker in $\mathrm{kDa}$; $\mathrm{H}$, total soluble protein extracts from non-inoculated leaves, negative control; lane 4, 6 and 8 , extracts from infiltrated leaves at 4, 6 and 8 dpi, respectively. $\mathbf{d}$ Western blot analysis of GFP from infiltrated $N$. benthamiana leaves. M, protein molecular weight marker in kDa; $\mathrm{H}$, total soluble protein extracts from non-inoculated leaves, negative control; lane 4,6 and 8, extracts from infiltrated leaves at 4, 6 and 8 dpi, respectively

showed a reduction in plant proteins after ethanol extraction (Fig. 3b), indicating that GFP was partly purified by the step. The $27-\mathrm{kDa}$ band was verified to be GFP by Western blot analysis (Fig. 3c). The purity of GFP was increased from $59.9 \%$ to about $87.3 \%$, with a yield of $58.5 \%$ (Table 1 ). In the second stage of this proceedure, the GFP was recovered into the aqueous phase by addition of $n$-butanol, which is more hydrophobic than ethanol. After configuration, the two phases were separated, and GFP effectively partitioned into the lower aqueous phase (Fig. 3a3). The volume of aqueous phase decreased, indicating that the GFP solution was concentrated simultaneously, as verified by both the Coomassie-stained polyacrylamide gel (Fig. 3b) and Western blot (Fig. 3c). This step also provided modest additional purification, because the purity of GFP was raised from $87.3 \%$ to about $89.4 \%$, with a yield of $51.2 \%$ (Table 1 ).

Because the aqueous phase may contain the residuals of organic solvents and salts, HIC chromatography was employed for their removal. A single peak was eluted (Fig. 3d) and silver-stained polyacrylamide gel analysis of purified recombinant GFP showed unique band of $27 \mathrm{kDa}$, even when high levels of GFP were examined (Fig. 3e). Overall purification resulted in GFP with purity above $95 \%$ and a yield of $34.1 \%$ (Table 1).

\section{The fluorescence characterization of purified GFP}

Fluorescence characterization of purified GFP was carried out using both gel-based imaging [17] and conventional spectrofluorometer-based method.

Because some kinds of alterations in GFP structure do not affect its chromophore fluorescence [18] and are not detectable using the spectrofluorometric method [17], gel-based imaging method, which is able to differentiate the alterations in GFP structure by relating the observed changes in the position of fluorescent bands, was employed to assess the structural changes of the purified GFP, which might take place during the purification process. GFP dilution samples, without heat treatment, were separated in a native discontinuous polyacrylamide gel. After electrophoresis, fluorescent image of GFP on the gel was captured using the Gel Doc XR (Bio-Rad) under UV illumination. The GFP bands were clearly visible in the gel under UV illumination, and no additional bands were observed (Fig. 4a), suggesting that the purification process did not cause detectable changes in GFP structure.

Table 1 Quantitative specifications of the principal stages of GFP purification

\begin{tabular}{lllll}
\hline Processing step & TSP $^{\mathrm{a}}(\mathrm{mg})$ & $\mathrm{GFP}^{\mathrm{b}}(\mathrm{mg})$ & Purity $^{\mathrm{c}}(\%)$ & $\mathrm{GFP}^{\text {Yield }}{ }^{\mathrm{d}}(\%)$ \\
\hline Extract & 13.7 & 8.2 & 59.9 & 100.0 \\
Ethanol extraction & 5.5 & 4.8 & 87.3 & 58.5 \\
n-butanol extraction & 4.7 & 4.2 & 89.4 & 51.2 \\
HiScreen Capto Butyl & 2.9 & 2.8 & 96.6 & 34.1 \\
\hline
\end{tabular}

${ }^{a}$ Amount of the TSP was determined according to BCA

${ }^{\mathrm{b}}$ Amount of the GFP was measured by the ELISA

'Purity is defined as the amount of GFP divided by the amount of TSP in the same sample

${ }^{\mathrm{d}}$ GFP Yield is defined as the amount of GFP recovered divided by initial amount of GFP in the crude extract of inoculated leaves 

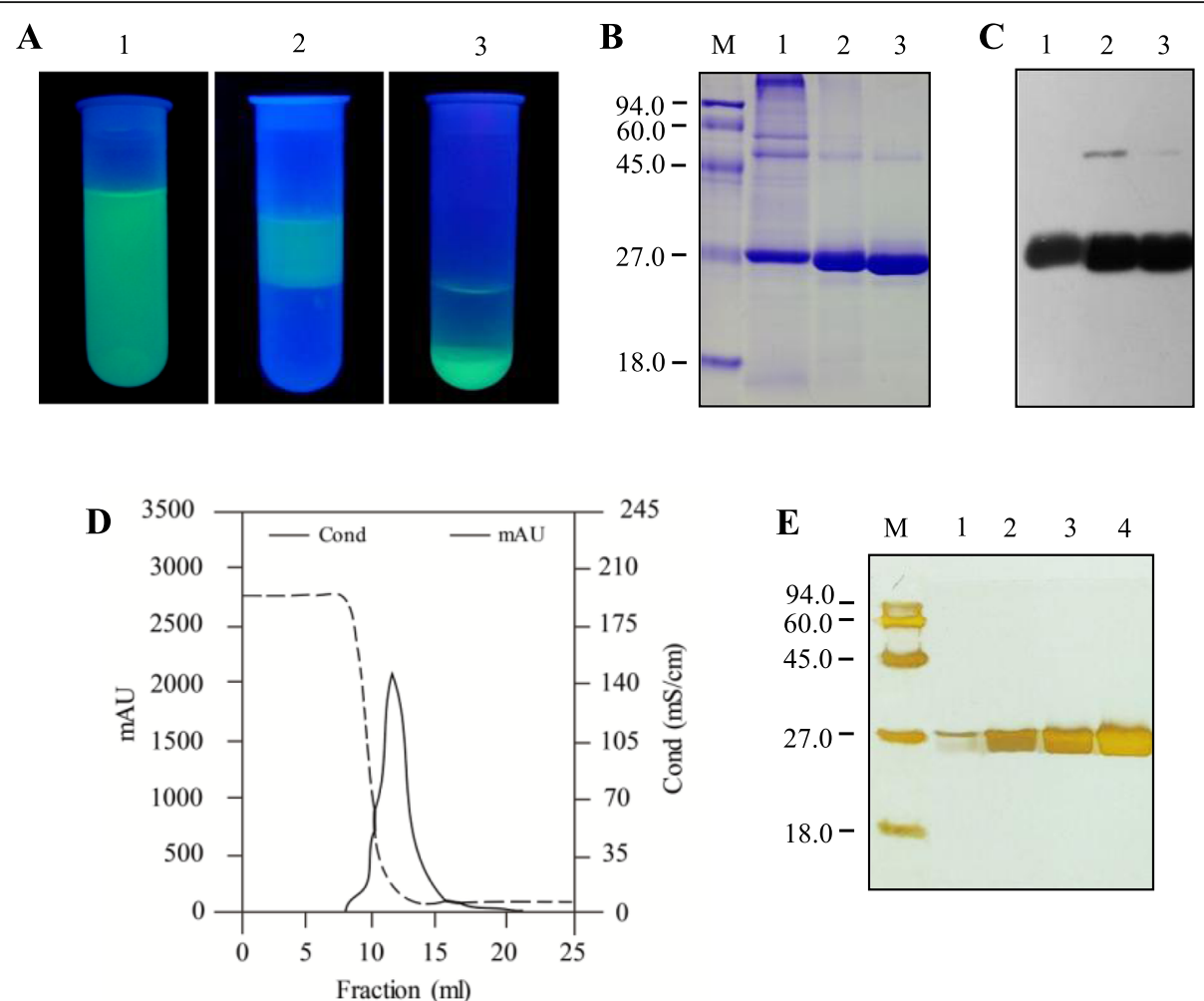

Fig. 3 Purification of GFP by alcohol/salt ATPS and HIC. a Successive fractions in the course of alcohol/salt ATPS procedures under UVillumination. 1, the supernatant of homogenate of infiltrated $N$. benthamiana leaves after centrifugation; 2 , the phase separation showing GFP in the upper ethanol phase after ethanol extraction; 3 , the phase separation showing GFP in the lower water phase after addition of $n$-butanol to the ethanol extract. b Analysis of the various GFP fractions from ATPS procedure by Coomassie-stained polyacrylamide gel. M, protein molecular weight marker in kDa; lanes 1, 2 and 3, the samples corresponding to the fractions from ATPS, as shown in a. c Immunoblot of the various GFP fractions in the course of ATPS. M, protein molecular weight marker in $\mathrm{kDa}$; lanes 1, 2 and 3, the samples corresponding to the fractions in the course of ATPS, as shown in b. $\mathbf{d}$ Elution curves of the GFP purified by HIC. e Silver-stained polyacrylamide gel showing the HIC purified GFP. M, Protein molecular weight marker in kDa; lane1, 2, 3 and 4, twofold serial dilution of purified GFP

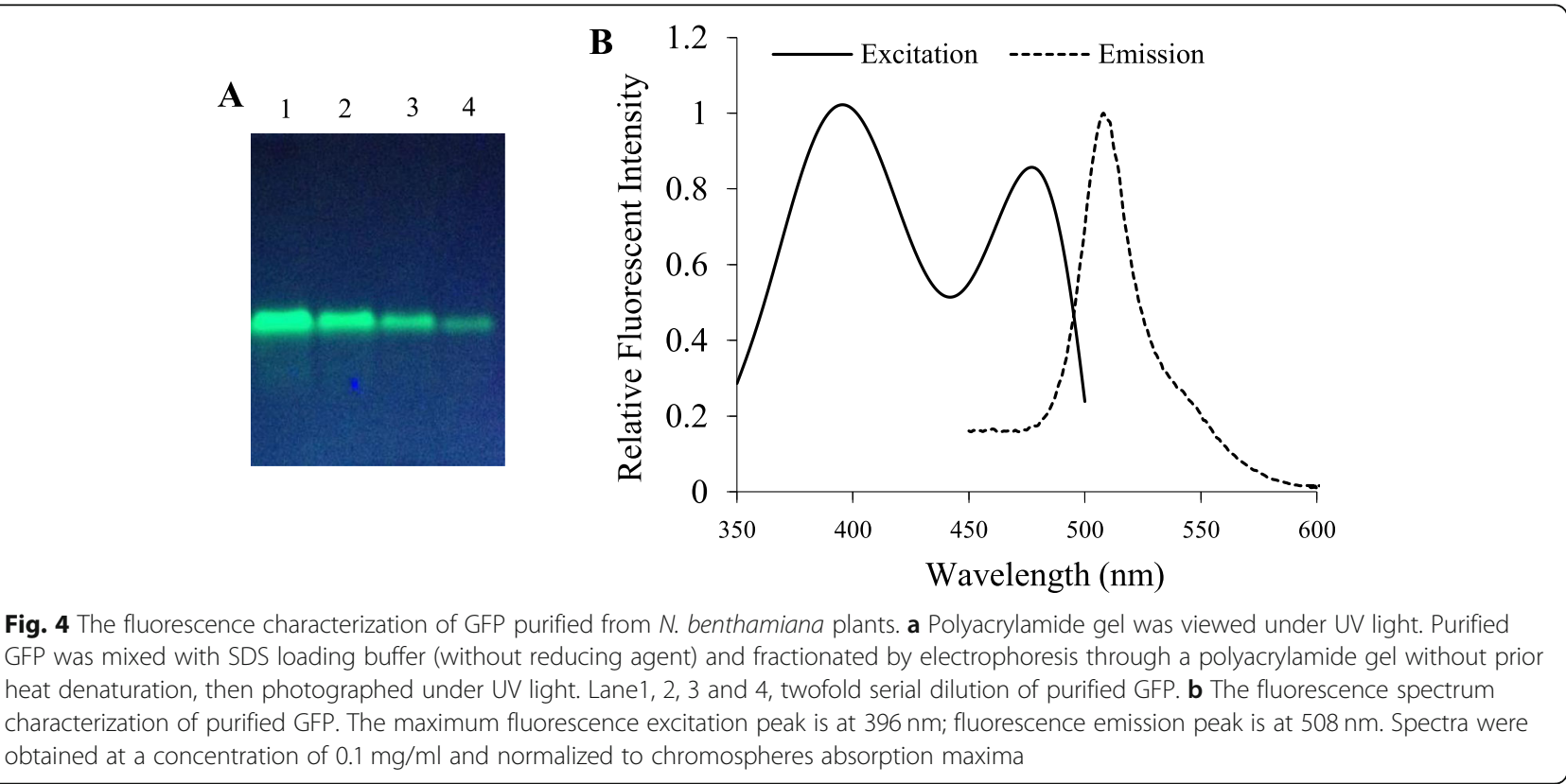


For spectrofluorometric analysis, samples were measured at the optimal excitation and emission wavelengths for GFP. Figure 4b shows the excitation and emission spectra of purified GFP from infected $N$. benthamiana. The emission spectrum shows a maximum at $505 \mathrm{~nm}$ and the excitation spectrum shows peaks at $395 \mathrm{~nm}$ and $470 \mathrm{~nm}$ (Fig. 4b). These spectroscopic properties are similar to those observed when GFP is purified by other methods.

\section{Discussion}

Plants are an attractive alternative platform for the production of recombinant protein [19]. It offers numerous potential advantages; including low capital equipment, low energy requirements, easy scale-up, reduced risk of carrying pathogen contamination, and ability to posttranslational modifications, etc. $[9,19]$. Plant viral vectors are widely used as powerful tools for expressing heterologous proteins in plants with inexpensive production costs [20]. Here, we employed the viral expression vector to transiently express recombinant GFP in $N$. benthamiana, which is commonly used for producing target proteins by plant viral vectors [21]. Using TMV expression vector (pJL TRBO-G) with the help of RNA silencing suppressor, recombinant GFP in soluble form was expressed at an extremely high level (up to $~ 60 \%$ of TSP) in less than 1 week in the $N$. benthamiana leaves. In term of the yield, the plant-produced GFP is comparable with that obtained from E. coli (generally ranges from $\sim 10 \%$ to $\sim 50 \%$ of total protein). Moreover, it has been estimated that purification and downstream processing of recombinant proteins represents $80-90 \%$ of the cost of producing pharmaceuticals [22]. GFP could be produced in both soluble form and insoluble inclusion bodies from $E$. coli over-expression system, depending on culturing conditions (such as low growth temperatures, co-overexpression of molecular chaperones, etc.) $[23,24]$. However, $\sim 10 \%$ to $\sim 20 \%$ of the recombinant GFP was found in the insoluble cell fraction even at optimal conditions [23]. Theoretically, the soluble form of plant-produced GFP may possess a good benefit for the cost reduction of the final GFP product. In addition, plant expression platform is more ecofriendly than the most of non-plant expression systems (such as bacteria, yeast, insect, and mammalian cell cultures, etc.). Altogether, we propose that the viral amplicon-based transient expression system is more suitable for the production of recombinant GFP than any other previously published method.

Currently, the various strategies, including chromatographic and non-chromatographic techniques, were developed to purify the recombinant GFP or its variants. Nevertheless, it is believed that the purification of GFP with the chromatographic methods generally involves multiple steps, time consuming, low throughput and of high cost [2]. In contrast, ATPS have been viewed as a potential alternative for protein purification because of its cost effectiveness and the simplicity of operation [5]. In addition, it is notable that alcohol/salt ATPS method is eco-friendly because ethanol and salt can be recycled. Although the yield of purified GFP could be considered modest in our study, alcohol/salt ATPS offers a considerably easier and faster way for purification of recombinant GFP. Otherwise, certain issues need to be considered while using alcohol/salt ATPS method in order to obtain effective GFP separation. Firstly, the soluble protein should be properly diluted before use, since GFP concentration exceeding $1.5 \mathrm{mg} / \mathrm{ml}$ can result in GFP coprecipitation with host proteins during phase separation. Secondly, operations should be performed at room temperature, because cooling can cause crystallization of ammonium sulfate. Lastly, exposure to ethanol can lead to a degree of protein denaturation. Thus, the step involving removing ethanol from the water-ethanol mixtures should be performed immediately.

The purpose of using HIC chromatography is initially to concentrate the sample and to remove the residuals of organic solvents and salts which may remain in the aqueous phase. However, we found that this step can further increase the GFP purity (from 89.4 to 96.6\%). We speculate that some compounds, which may not be stained with coomassie dye, were removed by the HIC process. Moreover, we also observed that a little amount of fluorescent proteins were deposited on the top of the HIC column and they cannot be eluted even by low-salt buffer. Comparing with ATPS purified samples (Fig. 3b and c), a doubtful dimer GFP band was missed in the HIC purified sample (Fig. 3e), indicating that the HIC process probably also remove the oligomer version of recombinant GFP (soluble aggregates) [25]. One may argue that a single step of HIC can be used to purify GFP because it has advantage of handling large volume of samples and yielding a good result in terms of purity and yield [26]. Unfortunately, plant extracts and homogenates contain unique compounds, such as pigments, phenolics, and etc. [27]. Those compounds, especially phenolics, present obstacles in the downstream processes since they can interact with the target proteins during purification [27]. Moreover, the hydrophobic plant pigments can strongly bind to HIC media, thereby seriously reducing the useful life-time of the media to a few cycles of operation [28]. Otherwise, re-generation of the HIC media with high-frequency is costly since it requires the use of organic solvents [28]. Therefore, pretreatment is highly needed and a single step of HIC might be unattractive in practice for recovery and purification of recombinant proteins from plant tissues. 
In this study, a strategy for producing GFP, which combines advantages of both plant virus-based expression platform and alcohol/salt ATPS, was developed. The high level of recombinant GFP was achieved by plant virus-based overexpression vector and the high yield adds to the economy of the downstream process. Moreover, the complete purification process requires only a few steps, takes only $\sim 4 \mathrm{~h}$ (Fig. 5 ) and recovers $34.1 \%$ of the protein, equivalent to a yield of $\sim 1.7 \mathrm{~g}$ of GFP per kilogram of $N$. benthaniana leaves. The purity of final GFP product was determined to be more than $95 \%$, and there were no changes in its spectroscopic characteristics. Although we did not experimentally compare our strategy with E. coli-based commercial strategy, two green technologies are involved in our strategy, thus making it more eco-friendly than what of the previously established methodologies. Accordingly, the developed expression and purification process in this study offer a cost-effective and concise alternative for the production of GFP.

\section{Conclusions}

In summary, our study proposed a strategy for producing recombinant GFP. The procedures include overexpressing recombinant GFP in tobacco leaves via viral amplicon-based vectors and downstream purification by alcohol/salt ATPS and HIC. The strategy possesses costefficient and eco-friendly aspects and thereby has considerable potential for the development of an efficient process for large-scale production of recombinant GFP.

\section{Methods}

\section{Plant materials and growth conditions}

$N$. benthamiana seeds were kindly provided by Dr. Yongjiang Zhang of the Chinese Academy of Inspection and Quarantine (CAIQ). N. benthamiana seedlings were grown at $22-25^{\circ} \mathrm{C}$ with $16 \mathrm{~h}$ dark period $/ 8 \mathrm{~h}$ light period and $65 \%$ humidity in small 5 in. diameter plastic pots.
All seedlings were watered on daily basis and supplemented with Hoagland solution once a week when required.

\section{Plasmids and Agrobacterium strains}

The plasmids pIL TRBO-G, pCBNoX P19 and Agrobacterium tumefaciens GV3101 were kindly provided by Dr. John A. Lindbo of the Ohio State University. pJL TRBOG, a Tobacco mosaic virus (TMV) RNA-based overexpression vector [16], was used to express GFP in $N$. benthamiana leaves using transient agroinfiltration. pCBNoX P19, expressing the 19-kDa silencing suppressor from Tomato bushy stunt virus (TBSV), was coinfiltrated with the pJL TRBO-G to prevent the RNAimediated gene silencing in plants. The plasmids were transformed into A. tumefaciens GV3101 using the freeze-thaw method.

\section{Agroinfiltration of $N$. benthamiana plants}

A. tumefaciens GV3101 carrying either pJL TRBO-G or pCBNoX P19, were grown in $4 \mathrm{ml} \mathrm{LB}$ medium for $24 \mathrm{~h}$ at $28{ }^{\circ} \mathrm{C}$ and shaking at $250 \mathrm{rpm}$. The cultures were then transferred into $100 \mathrm{ml} \mathrm{LB}$ medium having $200 \mu \mathrm{M}$ of acetosyringone (Sigma-Aldrich) grown overnight at $28^{\circ} \mathrm{C}$ and shaking at $250 \mathrm{rpm}$. Cells were harvested by centrifugation at $3000 \mathrm{~g}$ for $10 \mathrm{~min}$ and re-suspended in infiltration buffer ( $\mathrm{pH}$ 5.6, $10 \mathrm{mM}$ MES, $10 \mathrm{mM} \mathrm{MgCl}_{2}$ and $200 \mu \mathrm{M}$ acetosyringone) to achieve an $\mathrm{OD}_{600}$ of 0.4 . The pJL TRBO-G expression vector was mixed in a 1:1 volume ratio with the gene-silencing suppressor (pCBNoX P19). The mixed Agrobacterium suspensions were incubated in the dark at room temperature for 2-3 h before infiltration. The incubated Agrobacterium suspensions were infiltrated into the abaxial surface of leaves using a 1-ml syringe without needle. The agroinfiltrated plants were incubated in the growth chamber for 4-8 days after which the leaves were harvested.

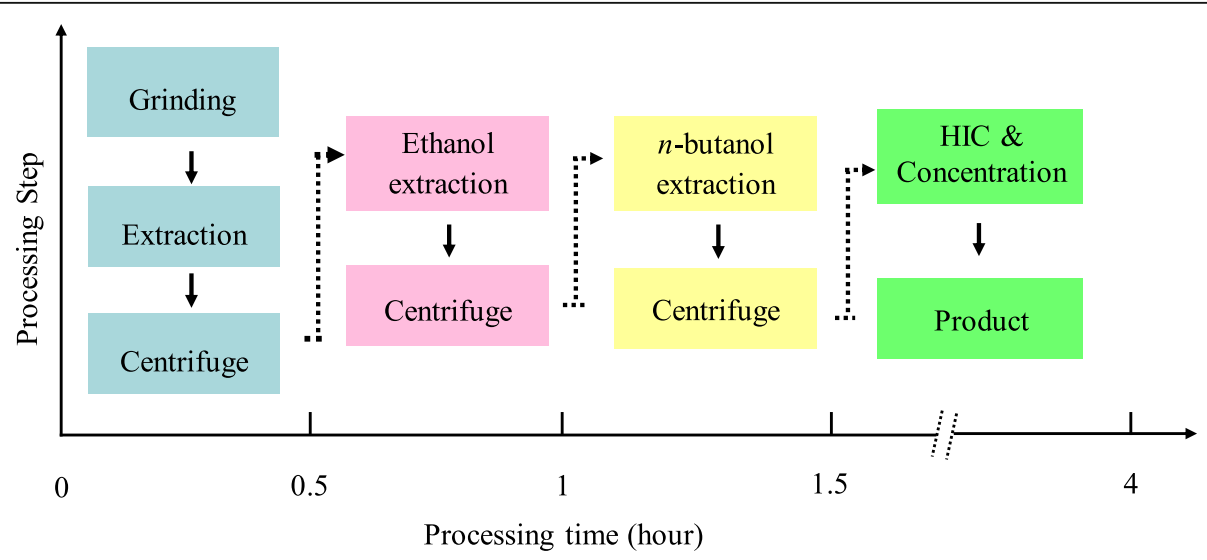

Fig. 5 The flow diagram of the purification of GFP from N. benthamiana plants 


\section{GFP imaging}

The GFP fluorescence was monitored by illumination with a hand-held long-wave UV source (UVP Blak-Ray 100AP) and was photographed with a Cannon G6 digital camera. For microscopic analysis, GFP-positive leaf cells were visualized using confocal laser scanning microscopy (Leica TCS STED Microscopy).

\section{Total soluble proteins (TSP) extraction and protein quantification}

Protein samples were prepared by freezing agroinfiltrated leaves in liquid nitrogen and grinding to a fine powder with a mortar and pestle. The Extraction Buffer (50 mM Tris- $\mathrm{HCl}, \mathrm{pH}$ 8.0, $150 \mathrm{mM} \mathrm{NaCl}, 10 \mathrm{mM}$ EDTA) was added into the leaf powder at a ratio of $1: 4(\mathrm{~g} / \mathrm{ml})$. Extracts were clarified by centrifugation at $12,000 \mathrm{~g}$ for $15 \mathrm{~min}$ at $4{ }^{\circ} \mathrm{C}$. The supernatant containing TSP was recovered. Total protein content was determined by BCA protein assay kit (Pierce). The concentration of GFP was measured by GFP ELISA Kit (Abcam) according to the manufacturer's specifications.

\section{Purification of GFP by alcohol/salt ATPS}

$0.3 \mathrm{ml}$ of $5 \mathrm{M} \mathrm{NaCl}$ and $2.33 \mathrm{ml}$ of saturated ammonium sulfate were added in turn to a 1-ml aliquot of TSP. Subsequently, the anhydrous ethanol was immediately added to the entire solution at a ratio of 1: 3 (volume-to-volume, v/v) and vigorously shaken for $30 \mathrm{~s}$. The phases were separated by centrifugation at $3000 \mathrm{~g}$ for $5 \mathrm{~min}$ and the upper ethanol phase containing GFP was carefully collected. Afterward, $n$-butanol was added to the ethanol extracts at a 1: 4 volume-to-volume ratio. After shaking and centrifugation as described above, the lower aqueous phase containing GFP was recovered.

\section{Purification of GFP by HIC}

AKTA Purifier system (GE Healthcare) equipped with an HIC column was used for further purification of GFP. Ammonium sulfate was added to aqueous phase obtained from the previous step up to the final concentration of $1.7 \mathrm{M}$. The solution was filtered through a $0.22 \mu \mathrm{m}$ filter (Millipore) and loaded onto 4.7-ml HiScreen Capto Butyl column (GE Healthcare) equilibrated with Binding Buffer $(10 \mathrm{mM}$ Tris- $\mathrm{HCl}, \mathrm{pH} 8.0,10 \mathrm{mM}$ EDTA, and $1.7 \mathrm{M}$ ammonium sulfate). After extensive washing with the Binding Buffer, the GFP was eluted at $1 \mathrm{ml} / \mathrm{min}$ with Elution Buffer $(10 \mathrm{mM}$ Tris- $\mathrm{HCl}, \mathrm{pH} 8.0$, $10 \mathrm{mM}$ EDTA).

\section{Sodium dodecyl sulfate-polyacrylamide gel electrophoresis (SDS-PAGE) and Western blot}

Protein samples were subjected to 12\% SDS-PAGE gels. After electrophoresis, gels were either stained with Coomassie brilliant blue or silver. For Western blot analysis, the proteins were transferred to a $0.45 \mu \mathrm{m}$ nitrocellulose membrane (Sigma-Aldrich) using semi-dry electrophoresis transfer (Bio-Rad Trans-Blot SD system). The blot was developed with rabbit anti-GFP antiserum (Abcam) diluted 1:5000, followed by secondary goat anti-rabbit antibody conjugated with alkaline phosphatase (Abcam). Specific immunoreactive proteins were detected using a Western Blot ECL Plus kit (GE Healthcare).

\section{Gel-based imaging}

Serial 2-fold dilutions of the purified GFP were prepared with double-distilled water. The diluted samples were mixed with SDS-PAGE gel-loading buffer (without reducing agent). A native and discontinuous polyacrylamide gel (PAGE) electrophoresis system was employed to fractionate the samples, with no prior heat treatment. Polyacrylamide gel with a $4 \%(\mathrm{w} / \mathrm{v})$ of stacking gel and a $15 \%(\mathrm{w} / \mathrm{v})$ of resolving gel were used in this study. After electrophoresis, the gel was captured using the Gel Doc XR (Bio-Rad).

\section{Fluorescence spectroscopy}

Samples were diluted in $10 \mathrm{mM}$ Tris- $\mathrm{HCl}, 10 \mathrm{mM}$ EDTA, $\mathrm{pH} 8.0$ buffers and fluorescence spectra were recorded on a Hitachi F-4500 spectrophotometer at room temperature. Excitation spectra were measured between 350 and 500 $\mathrm{nm}$ with the emission wavelength fixed at $508 \mathrm{~nm}$. Emission spectra were measured between 450 and $600 \mathrm{~nm}$ with the excitation wavelength fixed at $396 \mathrm{~nm}$.

\section{Abbreviations \\ A. tumefaciens: Agrobacterium tumefaciens; ATPS: Aqueous two-phase system; CaMV: Cauliflower mosaic virus; GFP: Green fluorescent protein; \\ HIC: Hydrophobic interaction chromatography; kDa: kilo-Dalton; N. benthamiana: Nicotiana benthamiana; rpm: rotation per minute; SDS- PAGE: Sodium dodecyl sulfate-polyacrylamide gel electrophoresis; TBSV: Tomato bushy stunt virus; TEV: Tobacco etch virus; TMV: Tobacco mosaic virus; TSP: Total soluble proteins; UV: Ultra-violet}

\section{Acknowledgements}

We would like to thank Dr. John A. Lindbo at The Ohio State University for generously providing the plasmid pJL TRBO-G, pCBNoX P19 and A. tumefaciens GV3101. We also thank Dr. K. Andrew White from York University, CA for editing the manuscript.

\section{Authors' contributions}

Conceived and designed the experiments: SW. Performed the experiments: JD. Analysed the data: XD. All authors read and approved the final manuscript.

\section{Funding}

This work was supported by the National Natural Science Foundation of China (Project No. 31660037 and No. 31060023). No funding body had any role in the design of the study and collection, analysis, and interpretation of data and in writing the manuscript.

Availability of data and materials

The datasets used and/or analysed in the current study are available from the corresponding author upon reasonable request.

Ethics approval and consent to participate Not applicable. 


\section{Consent for publication}

Not applicable.

\section{Competing interests}

The authors declare that they have no competing interests.

\section{Author details}

'Key Laboratory of Ministry of Education for Protection and Utilization of Special Biological Resources in the Western China, Yinchuan 750021, People's Republic of China. ${ }^{2}$ Key Laboratory of Modern Molecular Breeding for Dominant and Special Crops in Ningxia, Yinchuan 750021, People's Republic of China. ${ }^{3}$ School of Life Science, Ningxia University, 539 W. Helanshan Road, Yinchuan, Ningxia 750021, People's Republic of China.

Received: 1 August 2019 Accepted: 29 November 2019

Published online: 09 December 2019

\section{References}

1. Shimomura O, Johnson FH, Saiga Y. Extraction, purification and properties of aequorin, a bioluminescent protein from the luminous hydromedusan, Aequorea. J Cell Comp Physiol. 1962:59:223-9.

2. Cher Pin S, Poh En L, Zora T, Schian Pei L, Chien WO. Purification of the recombinant green fluorescent protein using aqueous two-phase system composed of recyclable $\mathrm{CO}_{2}$-based alkyl carbamate ionic liquid. Front Chem. 2018:6:529.

3. Wouters FS, Verveer PJ, Bastiaens PI. Imaging biochemistry inside cells. Trends Cell Biol. 2001;11:203-11.

4. Gerisch G, Albrecht R, Heizer C, Hodgkinson S, Maniak M. Chemoattractantcontrolled accumulation of coronin at the leading edge of Dictyostelium cells monitored using a green fluorescent protein-coronin fusion protein. Curr Biol. 1995;5:1280-5.

5. Lo SC, Ramanan RN, Tey BT, Tan WS, Show PL, Ling TC, Ooi CW. Purification of the recombinant enhanced green fluorescent protein from, Escherichia coli, using alcohol+salt aqueous two-phase systems. Sep Purif Technol. 2018;192:130-9.

6. Dos Santos NV, Martins M, Santos-Ebinuma VC, Ventura SP, Coutinho JA, Valentini SR, Pereira JF. Aqueous biphasic systems composed of cholinium chloride and polymers as effective platforms for the purification of recombinant green fluorescent protein. ACS Sustain Chem Eng. 2018;6: 9383-93.

7. Moustafa K, Makhzoum A, Trémouillaux-Guiller J. Molecular farming on rescue of pharma industry for next generations. Crit Rev Biotechnol. 2016; 36:840-50.

8. Scheller J, Henggeler D, Viviani A, Conrad U. Purification of spider silk-elastin from transgenic plants and application for human chondrocyte proliferation. Transgenic Res. 2004:13:51-7.

9. Hefferon K. Plant virus expression vectors: a powerhouse for global health. Biomedicines. 2017;5:44.

10. Obembe OO, Popoola JO, Leelavathi S, Reddy SV. Advances in plant molecular farming. Biotechnol Adv. 2011;29:210-22.

11. Merchuk JC, Andrews BA, Asenjo JA. Aqueous two-phase systems for protein separation: studies on phase inversion. J Chromatogr B. 1998; 711:285-93.

12. Yau YK, Ooi CW, Ng EP, Lan JCW, Ling TC, Show PL. Current applications of different type of aqueous two-phase systems. Bioresour Bioprocess. 2015;2:49.

13. Amid M, Shuhaimi M, Sarker MZI, Manap MYA. Purification of serine protease from mango (Mangifera Indica cv. Chokanan) peel using an alcohol/salt aqueous two phase system. Food Chem. 2012:132:1382-6.

14. Fu H, Yang ST, Xiu Z. Phase separation in a salting-out extraction system of ethanol-ammonium sulfate. Sep Purif Technol. 2015;148:32-7.

15. Soares PA, Vaz AF, Correia MT, Pessoa A Jr, Carneiro-da-Cunha MG Purification of bromelain from pineapple wastes by ethanol precipitation. Sep Purif Technol. 2012:98:389-95.

16. Lindbo JA. TRBO: a high-efficiency tobacco mosaic virus RNA-based overexpression vector. Plant Physiol. 2007:145:1232-40.

17. Chew FN, Tan WS, Tey BT. Fluorescent quantitation method for differentiating the nativity of green fluorescent protein. J Biosci Bioeng. 2011;111:246-8.
18. Melnik BS, Povarnitsyna TV, Melnik TN. Can the fluorescence of green fluorescent protein chromophore be related directly to the nativity of protein structure? Biochem Bioph Res Co. 2009;390:1167-70.

19. Lico C, Santi L, Twyman RM, Pezzotti M, Avesani L. The use of plants for the production of therapeutic human peptides. Plant Cell Rep. 2012;31:439-51.

20. Peyret $\mathrm{H}$, Lomonossoff GP. When plant virology met Agrobacterium: the rise of the deconstructed clones. Plant Biotechnol J. 2015;13:1121-35.

21. Goodin MM, Zaitlin D, Naidu RA, Lommel SA. Nicotiana benthamiana: its history and future as a model for plant-pathogen interactions. Mol PlantMicrobe Interact. 2008;21:1015-26.

22. Sabalza M, Christou P, Capell T. Recombinant plant-derived pharmaceutical proteins: current technical and economic bottlenecks. Biotechnol Lett. 2014; 36:2367-79.

23. Vera A, González-Montalbán N, Arís A, Villaverde A. The conformational quality of insoluble recombinant proteins is enhanced at low growth temperatures. Biotechnol Bioeng. 2007;96:1101-6.

24. Martínez-Alonso M, Vera A, Villaverde A. Role of the chaperone DnaK in protein solubility and conformational quality in inclusion body-forming Escherichia coli cells. FEMS Microbiol Lett. 2007;273:187-95.

25. Gonzalez-Montalban N, Garcia-Fruitos E, Villaverde A. Recombinant protein solubility_does more mean better? Nat Biotechnol. 2007;25:718.

26. Noor SSM, Tey BT, Tan WS, Ling TC, Ramanan RN, Ooi CW. Purification of recombinant green fluorescent protein from Escherichia coli using hydrophobic interaction chromatography. J Liq Chromatogr R T. 2014;37: 1873-84.

27. Wilken LR, Nikolov ZL. Recovery and purification of plant-made recombinant proteins. Biotechnol Adv. 2012;30:419-33.

28. Armah GE, Achel DG, Acquaah RA, Belew M. Purification of miraculin glycoprotein using tandem hydrophobic interaction chromatography: U.S. Patent 5,886,155; 1999 .

\section{Publisher's Note}

Springer Nature remains neutral with regard to jurisdictional claims in published maps and institutional affiliations.

Ready to submit your research? Choose BMC and benefit from:

- fast, convenient online submission

- thorough peer review by experienced researchers in your field

- rapid publication on acceptance

- support for research data, including large and complex data types

- gold Open Access which fosters wider collaboration and increased citations

- maximum visibility for your research: over $100 \mathrm{M}$ website views per year

At $\mathrm{BMC}$, research is always in progress.

Learn more biomedcentral.com/submissions 